\title{
Open Science and the Science-Society Relationship
}

\author{
Martin Lakomý ${ }^{1} \cdot$ Renata Hlavová ${ }^{2} \cdot$ Hana Machackova ${ }^{2}$
}

Published online: 24 June 2019

(C) The Author(s) 2019, Corrected Publication August/2019

\begin{abstract}
Nowadays, the prevailing trend in the science-society relationship is to engage with the broader public, which is beneficial for the public, scientific institutes, scientific findings, and the legitimacy of science as a whole. This article provides a broad review of the rapidly growing research on Open Science and identifies the gaps in the current knowledge for future research. The review focuses on the science-society relationship, such that knowledge from this field is summarised and systematised. Insight into the most salient topics, including science communication, public engagement with science, public cognition of science, and challenges and potential unintended consequences connected to interactions with the public are examined. The first section of the paper focuses on science communication which involves efforts and approaches to inform the public about science by the most effective means. The section on public engagement reviews how scientists and scientific institutions are increasingly involved in direct interactions with the public and different groups of stakeholders to make science more open. The section focusing on public cognition of science provides information about public knowledge, perception, and trust regarding science, which both determines and is formed by public engagement. Last, risks, ethical issues, and data issues connected to the implementation of Open Science principles are reviewed, as there are many unintended consequences of Open Science which are examined by this current research. In conclusion, research covering the science-society relationship is rapidly growing. However, it brings multiple challenges as well as opportunities which are captured and discussed in a variety of existing studies. This article provides a coherent overview of this field in order to bring more comprehensible knowledge to scientists, scientific institutions, and outreach professionals.
\end{abstract}

Keywords Science-society relationship $\cdot$ Open Science $\cdot$ Public involvement $\cdot$ Benefits $\cdot$ Challenges $\cdot$ Review

The relationship between science and society has been discussed with increasing frequency, and its improvement has been the main goal of Open Science (Cribb and Sari 2010; Destro Bisol et al. 2014; Martiny et al. 2016). Open Science is a practice aiming to make scientifically generated knowledge and its method of production more accessible, applicable, transparent, and responsive to the needs of both scientists and the public (Cribb and Sari 2010). These principles

The original version of this article was revised due to a retrospective Open Access order.

Martin Lakomý

lakomy@fss.muni.cz

1 Office for Population Studies/Department of Sociology, Faculty of Social Studies, Masaryk University, Brno, Czechia

2 Institute for Research on Children, Youth and Families, Faculty of Social Studies, Masaryk University, Brno, Czechia are also shared by the Responsible Research and Innovation (RRI) initiative, which is concerned with ethical, legal, and social implications of research (de Saille 2015; Owen et al. 2012), but also addresses various types of actors, such as scientists, policymakers, educators, business and industry innovators, and civil society (RRI Tools 2017). Therefore, communication with stakeholders, opening the research process, and engaging with the public, seems a major trend of the science-society relationship both on the academic (Cribb and Sari 2010; Martiny et al. 2016) and the institutional level (European Commission 2016).

Several authors have described the importance of science communication and public engagement (see Gregory and Miller 1998; Kaslow 2015; Scharrer et al. 2016; Thaler and Shiffman 2015). Specifically, Eagleman (2013) identified several reasons why science communication and public engagement with science are important. These include dissemination as a way of thanking taxpayers, who fund most of the research. Further, scientists are capable of inspiring critical 
thinking and initiate public debates within society, as well as to correct misinformation from the media. Science is also important in improving law and public policy, in explaining what science is and how to deal with scientific uncertainty. The public should also know how beautiful and complicated the scientific pursuit is, and as scientists are trained to think, write, speak, and discuss, they should do so to educate the public (Eagleman 2013). This field of research has been growing extensively and different topics have emerged in the current research on the science-society relationship, systematization for its users in terms of scientific institutions and various stakeholders including the public is needed.

To systematise current knowledge on the science-society relationship, we reviewed recent literature on the relationship between science and the public. The literature review drew on the most recent articles and books published since 2005 that are available in academic databases: EBSCO, Google Scholar, and Web of Science. This review is divided into four key topics - science communication, public engagement with science, public cognition of science, and the challenges of Open Science. Within each category, several subcategories could be identified (within brackets):

1) Science communication (how the public is informed, how people learn about science),

2) Public engagement with science (involvement in science, citizen science, science education),

3) Public cognition of science (perception of science, trust in science, public knowledge of science),

4) Challenges of Open Science (risks, ethical concerns, data issues).

\section{Science Communication - how the Public is Informed and how People Learn about Science}

The topics of science communication and learning about science are very close - the main distinction is a difference between communication of science/scientific outreach and learning about science from culture, media, and other sources. Scientific institutions have various opportunities to communicate their activities and results. A useful list of communication methods is provided by Domegan et al. (2010). These methods are consecutively ordered by their popularity amongst outreach professionals include: science weeks, websites, lectures and research seminars, open days, workshops, public talks and debates, science festivals, teacher information, printed media, travelling exhibits and kiosks, teacher training, specialised media, classroom courses, science shops, and other specific methods (Domegan et al. 2010).

The inception of modern science communication is dated to the $1970 \mathrm{~s}$, but most of the authors identify predecessors of this discipline in the nineteenth century (Knight 2006; Topham 2009), or as a part of the Enlightenment in the eighteenth century (Bensaude-Vincent and Blondel 2008; Bucchi and Trench 2008; Orthia 2016). Bucchi and Trench (2008) believe that the first scientific ideas were diffused amid the Enlightenment project in the eighteenth century. Afterwards, the intensity of science communication has fluctuated with the attractiveness of recent discoveries, but has remained to be an important part of science until the present (Bucchi and Trench 2008). With the differentiation and specialization of social systems (Parsons 1951), science communication has become a fully institutional scientific discipline (Bucchi and Trench 2008; Guenther and Joubert 2017). Nowadays, science communication has been increasingly emphasised due to an increased importance of scientific knowledge in other areas of human pursuits, which is a process labelled as the shift towards a 'knowledge society' (Abelson et al. 2003).

Despite the changing context, some main issues remained throughout the whole history of science communication, which include how to be effective, understandable, and accurate (Exley et al. 2015; Shea 2015). The effectiveness of science communication is an important topic, since it is presumed that science communication can change attitudes towards science (Bromme and Goldman 2014), increase interest in science (Logan and Skamp 2008; Retzbach and Maier 2015), and heighten science literacy (Tatalovic 2009; Thaler and Shiffman 2015; Treise and Weigold 2002), which concerns the understanding of basic scientific facts, methods, and the societal impacts of science (Bauer et al. 2007; Entradas 2015; Miller 1998).

However, despite the growing support of science communication and awareness of this goal amongst scientists (Bucchi and Trench 2008; Destro Bisol et al. 2014; Guenther and Joubert 2017), public scientific literacy and interest in science tend to be stable over time (Bauer et al. 2012; Eurobarometer 2013; Impey et al. 2011). There seems to be a gap in the efforts in science communication and its impact on the public, at least according to the empirical evidence. Some studies indicate an insufficient level of information provided to the general public (Domegan et al. 2010; Exley et al. 2015; Post 2016). For instance, the number of respondents who felt poorly informed about new scientific discoveries significantly outnumbered those well informed throughout the period 1989-2005 (Bauer et al. 2012). Therefore, further research on identifying the gaps in the communication of science and the implementation steps that can be most effective, is needed.

The effectiveness of science communication through various media closely relates to the specific forms and practices of communication, but also the factors and preferences of the recipients. Prior research already showed that utilised channels, and consequentially also the effectiveness of information transition differ by individual characteristics, such as education (Chang et al. 2017), gender, age (Lehmkuhl et al. 2016), 
and religiosity (Scheufele et al. 2009). Other studies illustrate that popular media not only transmit information about science, but also provide scientific education (Allgaier 2012; Szu et al. 2016), narrow the knowledge gap in society (Chang et al. 2017), and create various types of science perceptions and interpretations (Lörcher and Taddicken 2017).

With regard to diverse forms of communication, the educational process and personal communication remain the important sources of information about science. Apart from that, the general public receives the vast majority of its sciencerelated information from mass media (Chang et al. 2017; Maier et al. 2014; Schäfer 2011). According to Chang and colleagues (Chang et al. 2017), the most used channels of informing about science in descending order are: television, online newspaper, traditional newspaper, and social media. Apart from the communication made directly by scientists, the information is produced by journalists, but also amateurs (Morcillo et al. 2016; Schäfer 2011; Treise and Weigold 2002; Welbourne and Grant 2016). In addition, some more interactive forms of science communication have come in use as well, including science festivals (Bultitude 2014), science parties (Koolstra 2008), science cafés (Dijkstra 2017; Navid and Einsiedel 2012), social marketing techniques (Domegan et al. 2010), and stand-up comedies (Pinto et al. 2015), although these methods are more often conceptualised as forms of public engagement rather than science communication. Nevertheless, it is important to note that science communication and public engagement with science (which we discuss in the next section) are hard to distinguish properly, as the latter developed from the former. Additionally, the introduction of new communication technologies over the recent years brought many effective forms of communication with the public, such as blogs (Ranger and Bultitude 2016), YouTube channels (Allgaier 2012; Welbourne and Grant 2016), webcam remote views (Ehrenfreund et al. 2010), usage of online social networking sites, and other forms of computermediated communication (Grand et al. 2016).

\section{Public Engagement with Science, its Forms, and Consequences}

Public engagement with science is a broad set of techniques for transmitting the knowledge and improving the sciencepublic relationship (Dijkstra 2017; Ehrenfreund et al. 2010). Examples of the techniques are science cafés, science shops, deliberative workshops, needs surveys, focus groups, and many others (Engage2020 2015). To better understand its forms and functions, public engagement is further divided into two topics: science education and involvement/engagement in science in its narrower form. In general, the techniques and activities of public engagement evolved from science communication (Gemen et al. 2015), as the preferred model of science communication seems to be an interactive process (Cribb and Sari 2010; Gregory and Miller 1998) closer to a dialogue than to one-way mass communication (Mizumachi et al. 2011; Schäfer 2009). In this process, the information transmission is strongly interconnected with increasing science literacy and engagement of the public.

The area of science education is highly relevant, as learning is an integral part of every form of science communication (Bucchi and Trench 2008; Thaler and Shiffman 2015) or public engagement initiative (Dijkstra 2017; Jennett et al. 2016; Roger and Klistorner 2016). In this area, the shift from oneway science communication to interactive public engagement is also connected to the abandonment of the deficit model (Bauer et al. 2007; Besley and Tanner 2011; Logan 2001). The deficit model proposes that increasing public knowledge about science would lead to greater enthusiasm for science. However, its perspective disqualified the public from having relevant opinions. In response, more recent efforts shifted from the model excluding laypeople to the model stressing the dialogue and public participation (European Commission 2009; Gemen et al. 2015), which is strongly connected to abandoning a deficit perspective in favour of a contextual perspective (Besley and Tanner 2011; Entradas 2015). To sum up, a more informed and more involved public should form a 'knowledge society' (Abelson et al. 2003; Science and Technology Advisory Council 2013).

Communication in the media is one of the most important tools for the improvement of science education of the general public (Maier et al. 2014; Szu et al. 2016). However, science education also serves as a prerequisite for effective communication. The disseminated information cannot be oversimplified, and thus some prior knowledge of the topic is usually necessary for proper understanding (Dunwoody 2008; Shea 2015). Although the complexity of the message challenges understanding by a layperson (Bromme and Goldman 2014), a major simplification of the content in science communication would create distorted perceptions of both the content and science itself (Post 2016; Scharrer et al. 2016). The pre-understanding is gained via the educational process (Kuhn et al. 2017; McDermott and Kuhn 2012), or informal learning (Jennett et al. 2016; Maier et al. 2014). Learning by more traditional methods has its merit (Kuhn et al. 2017; Turney 2008), though using creative means - i.e. pictures, diagrams, charts (McDermott and Kuhn 2012), or even comics (Tatalovic 2009) - to describe science seems even more effective.

The area of public involvement in science is also broad, but we can distinguish its three forms: (i) informal discussions with scientists, (ii) decision-making about funding of science, and (iii) participation in citizen science projects. First, informal discussions include science festivals (Bultitude et al. 2011) and science cafés (Dijkstra 2017). Second, events concerning science financing can be divided into standard 
funding policy decisions (Rowe et al. 2010), participatory budgeting (Medvecky and Macknight 2017), and civic crowdfunding. Civic crowdfunding contains not only a selection of appropriate research projects for financing, but also funding itself made by the public (Stiver et al. 2015). Last, citizen science projects are hard to categorise, since they are all based on the common feature of public participation in scientific research (Riesch et al. 2013). In general, citizen science involves the public in a large number of projects, for example by providing an opportunity to help with data collection and data processing, or to participate in decision-making regarding the research process (Bonney et al. 2016). All these types of involvement do not focus only on the general public, but various types of stakeholders including citizen organizations and politicians (Alender 2016; Prpic 2011).

Public involvement projects do not only aim to educate, but also to increase interest in science, and to interact with diverse audiences (Bultitude 2014; Jensen and Buckley 2014). These factors and other goals of public involvement in science are in line with a shift from informing the public, towards public engagement in discussions, procedures, and governance in the area of Open Science and elsewhere (Abelson et al. 2003; European Commission 2009; Gemen et al. 2015). Bultitude (2014) with Jensen and Buckley (2014) illustrate the usefulness of science festivals as one technique of public involvement for arranging informal communication and making science more engaging. Citizen science projects also proved to be beneficial, especially for gaining new knowledge (Bonney et al. 2016; Land-Zandstra et al. 2016; Masters et al. 2016), producing new findings by non-scientists themselves (Alender 2016; Stodden 2010), promoting a dialogue amongst citizens and science (Del Savio et al. 2016; Dickerson-Lange et al. 2016; Roger and Klistorner 2016), and giving the agency to citizens (Del Savio et al. 2016).

Though public engagement has many merits, there still prevail many barriers in its wider implementation. For instance, despite the recent efforts of the European Commission (2009), the diffusion of public engagement activities is not widely present across the European Union, as these activities face many barriers (Gemen et al. 2015; Neresini and Bucchi 2011) 'linked both to participation fatigue, and structural and organisational hurdles to implement a legitimate participatory design in policy making' (Gemen et al. 2015, p. 63). Furthermore, it should be noted that the tendency for being engaged depends on the family background, education, socio-economic position, age, gender, and ethnicity (Bultitude et al. 2011; Jensen and Buckley 2014; von Roten and Moeschler 2007). Therefore, the potential to develop public engagement with science varies across countries, since these factors also differ on the country level. Moreover, countries with very little tradition of public discussions on science and technology (Felt and Fochler 2008) need more time and effort to institutionalise these activities. An example of countries with a weak tradition of public discussions is Austria, in which public engagement with science is welcomed on an abstract level, while the public sees most of the particular forms of participation as controversial (Felt and Fochler 2008). Therefore, the context-sensitivity is important in this matter, though many issues connected to public engagement with science are shared across European countries (Gemen et al. 2015; Neresini and Bucchi 2011).

\section{Public Cognition of Science - Perception, Trust, and Knowledge}

Public cognition of science denotes everything the public knows and thinks about science, while the previous topics focused on the processes of formatting knowledge and attitudes. Public cognition encompasses public perception of science and attitudes towards science, the topic of trust in science, and public knowledge overlapping with public understanding of science. These three dimensions - which are further labelled as the perception of science, trust in science, and public knowledge - are distinctive, but still related, as they reflect some ideas and information that citizens possess.

Public perception of science is a very diverse field of research, even when defined narrowly. Prior research focused on perceptions of science across diverse contexts (science in school, work in science, science outside school; see Kind et al. 2010) and both generic and specific topics (science in general, nuclear power, genetic medicine, genetically-modified food, environmental science, etc.; Allum et al. 2008; Kind et al. 2010). Some studies also addressed the perception of science communication itself (Dijkstra and Gutteling 2012) or the perception of science by students as potential scientists which might thereby impact the future development of science (Impey et al. 2011; Osborne et al. 2003).

Trust in sources of scientific information is rooted in, but not determined by, general trust, and affects processing of information about science (Brewer and Ley 2013). Trust in science is a multidimensional concept, which can be oriented towards diverse actors or areas, such as scientists themselves, and also scientists from different fields, scientific institutions, utilised methodology, or presented findings. Although the trust in scientists and university professors is amongst the highest compared to other professions and organizations (Luján and Todt 2007), and it has increased in many European countries (Evans 2014), its less than stable level is a serious issue threatening the legitimacy of science in the context of more sceptical knowledge societies (Brewer and Ley 2013; Inglehart 1990). Brewer and Ley (2013) found that public trust in some sources of scientific information (e.g. newspaper and television news) is considerably lower than trust in more specialised sources of information, such as science magazines and science television. These findings make 
trust in science an important topic in designing specific communication strategies, which should provide information in precise, as well as, comprehensive and credible ways.

Public knowledge of science has been a part of the deficit model regarding the public and is also known as science literacy (Allum et al. 2008). Hence, public knowledge of science has been formerly studied as objective knowledge worth improving, while more recent research focuses especially on the link of science literacy with perception of science and trust in science (Allum et al. 2008; Cook et al. 2011; Impey et al. 2011). A meta-analysis of 193 nationally representative surveys has shown that science literacy has a weak, but positive association with attitudes towards science (Allum et al. 2008). Increasing science literacy is one of the aims of Open Science, as it leads to more informed discussion, knowledge-based decision-making, and democratic science beneficial for both scientists and the public (Entradas 2015).

Although a greater focus is put on public engagement and science communication, the topic of public cognition is important as well. As Luján and Todt (2007) argue, public concerns related to the undesired effects of science and technology are evident in the context of the European Union. This is not surprising, since many European countries are labelled as post-industrial, and especially post-industrial countries are characterised by having more sceptical citizens examining scientific findings themselves (Allum et al. 2008; Inglehart 1990). Consequently, this factor leads to less stable levels of trust and attitudes towards science, even though they can be high for some contexts and institutions, which threatens the legitimacy of science as an institution (Brewer and Ley 2013; Eagleman 2013). Bauer and colleagues (Bauer et al. 2007) believe that public participation in science is a way to rebuild public trust. Thus, the improved perception of science should be one of the aims of every public engagement or science communication activity.

\section{Challenges of Open Science - Risks, Ethical Concerns, and Data Issues}

The final part reviews challenges related to Open Science. While the previous sections introduced some concerns related to the perception of science, this section focuses on challenges and concerns that specifically address Open Science. These need to be reviewed to get a better grasp of both the benefits and drawbacks of Open Science, which also need to be considered in its implementation and evaluation. Specifically, we will review three salient challenges associated with Open Science: risks, ethical concerns, and data issues.

Implementation of Open Science does not only bring benefits in the form of more effective science production and democratization of the whole process (Eagleman 2013; Watson 2015), but also related risks (Ahram et al. 2013;
Master et al. 2013). These risks should not be confused with barriers, such as lack of awareness (Grigorov 2014), closed disciplinary research culture, settings of scientific institutions (Friesike et al. 2015), and funding procedures supporting privatised production of findings (Majumder et al. 2016; Watson 2015).

The risks related to Open Science implementation can be defined as potentially harmful consequences of Open Science and in many cases involve possible risks for research participants, scientists, and funders. Some most common examples are lost authorship, misuse of personal data by scientific institutions or third parties, disruption of privacy, and data utilization for harmful or ethically/religiously unacceptable research (Ahram et al. 2013; Capocasa et al. 2016; Friesike et al. 2015; Joly et al. 2015). The risks of Open Science are obviously interconnected with ethical concerns. Ethical issues, as well as perceived risks, are most often connected to research collecting highly sensitive data, such as biomedical and genomic research (Capocasa et al. 2016; Joly et al. 2015). Another segment of research on ethical issues examines how this topic is addressed in science communication in order to inform the public in a proper way (Hendriks et al. 2016; Post 2016). Prior research in this area emphasises two common concerns. First, although ethics committees usually need to approve research on ethically controversial topics, these committees and their rules depend strongly on legislation, and various approaches towards data sharing and confidentiality may complicate accessing comparable forms of Open Science across countries (Capocasa et al. 2016). Second, ethically controversial research has a deteriorating effect on science in reducing willingness to participate in research and to trust in science generally (Ahram et al. 2013; Hendriks et al. 2016; Majumder et al. 2016). Thus, the topic of ethical issues, their communication and public perceptions need to be studied further, as it shapes both the credibility and effectiveness of science.

The topic of data issues in Open Science is connected to risks through potential data misuse (Joly et al. 2015) and to ethical issues through questions of privacy and confidentiality (Majumder et al. 2016). Moreover, the importance of Open Data - the frequently discussed topic, in which potential consequences for society are not adequately reflected - for science efficiency, reproducibility, and credibility are also elaborated in terms of whether these three aims should be fulfilled. These doubts are based on potential risks of open data for scientists and research participants including data misuse, ownership, and additional costs (Bull et al. 2015; Destro Bisol et al. 2014). Especially the principle of effectiveness of scientific research and the potential of improving the sciencesociety relationship for an increase or decrease of effectiveness are discussed broadly (Bull et al. 2015; Eagleman 2013; Watson 2015). The principle of Open Data suffers from the same barriers as Open Science itself, namely the lack of awareness, missing institutional motivation, missing 
knowledge of the right procedures, and funding issues (Destro Bisol et al. 2014; Grand et al. 2016). Hence, further initiatives should aim for a shift within scientific institutions towards more open, interactive, and responsible actors and simultaneous reflection of its potential drawbacks.

\section{Conclusions and Discussion}

This article provides an overview of current knowledge in the area of Open Science and its relationship to the public and identifies the opportunities for future research. Our review of recent literature on the relationship between science and society identified and depicted four main interrelated topics studied in this area. First, the field of science communication examines the methods of informing the public about the science (by traditional or innovative means), ways of informing the public about engagement events, and methods of addressing different types of citizens by the most effective means. Second, public engagement with science, which is currently an expanding area overlapping with scientific communication, comprises also different techniques and events for the active involvement of the public in the scientific process and dissemination. Public engagement comprises interactions between scientists and non-scientists as well as the participation of laypeople in various stages of the scientific project. Third, the research on public cognition of science provides information about public knowledge and perceptions of science (including trust in science), which both determine and are being formed by public engagement. Finally, the implementation of Open Science principles has many challenges, which are examined by research on the topics of risks, ethical concerns, and data issues.

Despite the extensive knowledge related to the Open Science, we want to highlight several gaps and questions, which should be addressed in further research. First, acknowledging the importance of establishing and sustaining effective communication with the public, future studies should focus on studying and developing new ways of informing and engaging the public (Ehrenfreund et al. 2010). Specifically, they should explore preferences in science communication in different target groups, which is a particularly understudied topic. While many existing surveys asked for common ways of receiving information about science, no study inquired personal preferences in acquiring this information. The need of such research is also supported by the fact that used means of communication are not identical to preferred means, as the used means depend strongly on the actual accessibility of particular means (Gelmez Burakgazi and Yildirim 2014). This paper argues that the identification of preferred means of science communication can increase the volume of received information and make the communication more effective. Moreover, improvement of science communication is believed to approach and involve also people uninterested in science (Kawamoto et al. 2013). Thus, it is important to optimise the methods of science communication to increase its effectivity, as it can be beneficial in several ways.

Second, various proposals addressed the aim to increase the overall levels of the public engagement. However, less pronounced is the issue that science should not only aim for a higher number of individuals being engaged, but also to involve different types of actors in order to be really open to diverse segments of the public, and, in essence, be more democratic (Eagleman 2013; Entradas 2015). In order to achieve this, particular motivations and effectivity of various incentives for an involvement of different groups of the public, especially those who tend to be less or not at all engaged, should be examined more deeply. At the same time, it is important to reflect culture-specific barriers of public engagement and generally the limits of this endeavour for each society and individual (Felt and Fochler 2008) and accordingly adjust the possibilities of participatory activities.

Third, the topic of trust in science illustrates that the four areas examined by this paper are not separated, but associated in a complex manner. Specifically, trust in science shapes utilised channels, as well as frequency of receiving information about science, while, concurrently, this communication affects trust and attitudes towards science (Retzbach and Maier 2015; Takahashi and Tandoc Jr 2016). The same applies for the more interactive forms of scientific communication - public engagement in science (Muñoz et al. 2012; Retzbach and Otto 2016). Moreover, it should be noted that trust in science may change in quantity as well as in quality amid the knowledge society (Brewer and Ley 2013; Inglehart 1990). Since trust is a multidimensional phenomenon, we should be more aware and attentive towards diverse aspects related to trust - and distrust - amongst the public. As the public is getting more knowledgeable about many areas of society including science, this goes hand-in-hand with a necessary level of scepticism and desire to participate in important decisions. Thus, future research should aim to examine these aspects accordingly.

Finally, if we consider that increasing knowledge may increase scepticism amongst the public, it should be also acknowledged that this process, which is usually seen as beneficial within Open Science initiatives, can also be associated with several challenges to Open Science. Amongst these challenges is higher concern regarding ethical issues or hesitation over providing any data for scientific purposes leading to lower trust in science (Ahram et al. 2013; Hendriks et al. 2016). In this manner, Open Science and the efforts to achieve a more informed public may extend some concerns related to science caused by higher reflectivity and engagement of the public. This is an important aspect of Open Science, which needs to be stressed and further elaborated in Open Science efforts. Nevertheless, this concern should not be considered a barrier 
which limits the efforts of Open Science, but as an aspect which needs to be dealt with care. It should also be stressed that knowledgeable actors make more informed decisions, which is a goal of scientific research, and thus the improvement of public knowledge of science and its specifics in the context of a knowledge society need to be both further studied and better developed in applied research.

To conclude, our review provides deep insight into key topics related to Open Science. However, it also sheds some light on gaps and challenges within current research and gives some guidance to future studies to help fill the gaps identified within Open Science research. Amongst others, new ways of informing and engaging the public should be developed, and preferences in science communication within different target groups should be explored. Further, the topics of ethical issues, their communication, and public perceptions need to be studied, while further initiatives should aim for a shift within scientific institutions towards more open, interactive, and responsible actors and simultaneous reflection of its potential drawbacks.

Acknowledgments This project has received funding from the European Union's Horizon 2020 research and innovation programme under Grant Agreement No. 741527.

Open Access This article is distributed under the terms of the Creative Commons Attribution 4.0 International License (http:// creativecommons.org/licenses/by/4.0/), which permits use, duplication, adaptation, distribution and reproduction in any medium or format, as long as you give appropriate credit to the original author(s) and the source, provide a link to the Creative Commons license and indicate if changes were made.

\section{Further Reading}

Abelson, J., Forest, P. G., Eyles, J., Smith, P., Martin, E., \& Gauvin, F. P. 2003. Deliberations about deliberative methods: Issues in the design and evaluation of public participation processes. Social Science and Medicine. https://doi.org/10.1016/S0277-9536(02)00343-X.

Ahram, M., Othman, A., Shahrouri, M., \& Mustafa, E. 2013. Factors influencing public participation in biobanking. European Journal of Human Genetics, 22(4), 445-451. https://doi.org/10.1038/ejhg. 2013.174

Alender, B. 2016. Understanding volunteer motivations to participate in citizen science projects: A Deeper look at water quality monitoring. Journal of Science Communication, 15(3), A04.

Allgaier, J. 2012. On the Shoulders of YouTube: Science in Music Videos. Science Communication, 35(2), 266-275. https://doi.org/ 10.1177/1075547012454949.

Allum, N., Sturgis, P., Tabourazi, D., \& Brunton-Smith, I. 2008. Science knowledge and attitudes across cultures: a meta-analysis. Public Understanding of Science, 17(1), 35-54. https://doi.org/10.1177/ 0963662506070159.

Bauer, M. W., Allum, N., \& Miller, S. 2007. What can we learn from 25 years of PUS survey research? Liberating and expanding the agenda. Public Understanding of Science, 16(1), 79-95. https:// doi.org/10.1177/0963662506071287.
Bauer, M. W., Shukla, R., \& Kakkar, P. 2012. Public Understanding of Science in Europe 1989-2005: A Eurobarometer Trend File. Cologne. https://doi.org/10.4232/1.11382.

Bensaude-Vincent, B., \& Blondel, C. 2008. Science and Spectacle in the European Enlightenment. Aldershot:Ashgate.

Besley, J. C., \& Tanner, A. H. 2011. What Science Communication Scholars Think About Training Scientists to Communicate. Science Communication, 33(2), 239-263. https://doi.org/10.1177/ 1075547010386972.

Bonney, R., Phillips, T. B., Ballard, H. L., \& Enck, J. W. 2016. Can citizen science enhance public understanding of science? Public Undersanding of Science, 25(1), 2-16. https://doi.org/10.1177/ 0963662515607406

Brewer, P. R., \& Ley, B. L. 2013. Whose Science Do You Believe?Explaining Trust in Sources of Scientific Information About the Environment. Science Communication, 35(1), 115-137. https://doi.org/10.1177/1075547012441691.

Bromme, R., \& Goldman, S. R. 2014. The Public's Bounded Understanding of Science. Educational Psychologist, 49(2), 5969. https://doi.org/10.1080/00461520.2014.921572.

Bucchi, M., \& Trench, B. 2008. Handbook of public communication of science and technology. Abingdon:Routledge.

Bull, S., Roberts, N., \& Parker, M. 2015. Views of Ethical Best Practices in Sharing Individual-Level Data From Medical and Public Health Research: A Systematic Scoping Review. Journal of Empirical Research on Human Research Ethics, 10(3), 225-238. https://doi. org/10.1177/1556264615594767.

Bultitude, K. 2014. Comment Science festivals: do they succeed in reaching beyond the 'already engaged. Journal of Science Communication, 13(4), C01.

Bultitude, K., McDonald, D., \& Custead, S. 2011. The rise and rise of Science Festivals - an international review of organised events to celebrate science. International Journal of Science Education, 1(2), 165-188.

Capocasa, M., Anagnostou, P., D’Abramo, F., Matteucci, G., Dominici, V., Destro Bisol, G., \& Rufo, F. 2016. Samples and data accessibility in research biobanks: an explorative survey. PeerJ, 4, e1613. https:// doi.org/10.7717/peerj.1613.

Chang, J., Kim, S., Kang, M., Shim, J. C., \& Ma, D. H. 2017. The gap in scientific knowledge and role of science communication in South Korea. Public Understanding of Science, 26, 1-16. https://doi.org/ 10.1177/0963662516685487.

Cook, S. B., Druger, M., \& Ploutz-Snyder, L. L. 2011. Scienti fi c literacy and attitudes towards American space exploration among college undergraduates. Space Policy, 27(1), 48-52. https://doi.org/10. 1016/j.spacepol.2010.12.001.

Cribb, J., \& Sari, T. 2010. Open science: shaking knowledge in the global century. Collingwood:CSIRO Publishing.

de Saille, S. 2015. Innovating innovation policy: the emergence of 'Responsible Research and Innovation. Journal of Responsible Innovation, 2(2), 152-168. https://doi.org/10.1080/23299460. 2015.1045280.

Del Savio, L., Prainsack, B., \& Buyx, A. 2016. Crowdsourcing the Human Gut. Is crowdsourcing also 'citizen science. Journal of Science Communication, 15(03), A03.

Destro Bisol, G., Anagnostou, P., Capocasa, M., Bencivelli, S., Cerroni, A., Contreras, J., ... Boulton, G. 2014. Perspectives on Open Science and scientific data sharing: an interdisciplinary workshop. Journal of Anthropological Sciences, 92, 179-200. https://doi.org/ 10.4436/JASS.92006

Dickerson-Lange, S. E., Bradley Eitel, K., Dorsey, L., Link, T. E., \& Lundquist, J. D. 2016. Challenges and successes in engaging citizen scientists to observe snow cover: from public engagement to an educational collaboration. Journal of Science Communication, 15(01), A01. 
Dijkstra, A. M. 2017. Analysing Dutch Science Cafés to better understand the science-society relationship. Journal of Science Communication, 16(1), A03.

Dijkstra, A. M., \& Gutteling, J. M. 2012. Communicative Aspects of the Public-Science Relationship Explored: Results of Focus Group Discussions About Biotechnology and Genomics. Science Communication, 34(3), 363-391. https://doi.org/10.1177/ 1075547011417894.

Domegan, C., Davidson, K., \& McCauley, V. 2010. Realising the Management Challenges for Science Communication Outreach: A Social Marketing Perspective. Irish Journal of Management, 30(1), 89-109.

Dunwoody, S. 2008. Science journalism. In M. Bucchi, \& B. Trench (Eds.), Handbook of Public Communication of Science and Technology (pp. 15-26). Abingdon: Routledge.

Eagleman, D. M. 2013. Why Public Dissemination of Science Matters: A Manifesto. The Journal of Neuroscience, 33(30), 12147-12149. https://doi.org/10.1523/JNEUROSCI.2556-13.2013.

Ehrenfreund, P., Peter, N., \& Billings, L. 2010. Acta Astronautica Building long-term constituencies for space exploration: The challenge of raising public awareness and engagement in the United States and in Europe. Acta Astronautica, 67(3), 502-512. https:// doi.org/10.1016/j.actaastro.2010.03.002.

Engage2020. 2015. Action Catalogue. Retrieved September 5, 2017, from http://actioncatalogue.eu/. Accessed 5 Sept 2017

Entradas, M. 2015. Science and the public: The public understanding of science and its measurements. Portuguese Journal of Social Science, 14(1), 71-85. https://doi.org/10.1386/pjss.14.1.71.

Eurobarometer. 2013. Responsible Research and Innovation (RRI), Science and Technology, (November).

European Commission. 2009. Challenging Futures of Science in Society: Emerging trends and cutting-edge issues. Report of the MASIS Expert Group Setup by the European Commission. EUR 24039, $80 \mathrm{~S}$. https://doi.org/10.2777/467

European Commission. 2016. EU Open Innovation, Open Science, Open to the World. European Comission. Luxembourg: Publications Office of the European Union. https://doi.org/10.2777/061652

Evans, J. H. 2014. Faith in science in global perspective: Implications for transhumanism. Public Understanding of Science, 23(7), 814-832. https://doi.org/10.1177/0963662514523712.

Exley, K., Cano, N., Aerts, D., Biot, P., Casteleyn, L., Kolossa-gehring, M., ... Sepai, O. 2015. Communication in a Human biomonitoring study: Focus group work, public engagement and lessons learnt in 17 European countries. Environmental Research, 141, 31-41. https://doi.org/10.1016/j.envres.2014.12.003

Felt, U., \& Fochler, M. 2008. The bottom-up meanings of the concept of public participation in science and technology. Science and Public Policy, 35(7), 489-499. https://doi.org/10.3152/030234208X329086.

Friesike, S., Widenmayer, B., Gassmann, O., \& Schildhauer, T. 2015. Opening science: towards an agenda of open science in academia and industry. Journal of Technology Transfer, 40, 581-601. https:// doi.org/10.1007/s10961-014-9375-6.

Gelmez Burakgazi, S., \& Yildirim, A. 2014. Accessing Science Through Media: Uses and Gratifications Among Fourth and Fifth Graders for Science Learning. Science Communication, 36(2), 168-193. https:// doi.org/10.1177/1075547013505847.

Gemen, R., Breda, J., Coutinho, D., Celemín, L. F., Khan, S., Kugelberg, S., ... Hadwiger, K. 2015. Stakeholder engagement in food and health innovation research programming - key learnings and policy recommendations from the INPROFOOD project. Nutrition Bulletin, 40(1), 54-65. https://doi.org/10.1111/nbu.12127

Grand, A., Holliman, R., Collins, T., \& Adams, A. 2016. "We muddle our way through": shared and distributed expertise in digital engagement with research. Journal of Science Communication, 15(4), A05.

Gregory, J., \& Miller, S. 1998. Science in public: Communication, culture, and credibility. Cambridge:Basic Books.
Grigorov, I. 2014. Importance \& benefits of Open Science for ubiquitous, sharing, dissemination \& impact. Veliko Tarnovo: FOSTER Open Science.

Guenther, L., \& Joubert, M. 2017. Science communication as a field of research: identifying trends, challenges and gaps by analysing research papers. Journal of Science Communication, 16(2), A02.

Hendriks, F., Kienhues, D., \& Bromme, R. 2016. Evoking vigilance: Would you (dis)trust a scientist who discusses ethical implications of research in a science blog? Public Understanding of Science, 25(8), 992-1008. https://doi.org/10.1177/0963662516646048.

Impey, B. C., Buxner, S., Antonellis, J., Johnson, E., \& King, C. 2011. A Twenty-Year Survey of Science Literacy Among College Undergraduates. Journal of College Science Teaching, 40(4), 31-38.

Inglehart, R. 1990. Culture Shift in Advanced Industrial Society. Princeton:Princeton University Press.

Jennett, C., Kloetzer, L., Schneider, D., Iacovides, I., Cox, A. L., Gold, M., ... Talsi, Y. 2016. Motivations, learning and creativity in online citizen science. Journal of Science Communication, 15(03), A05.

Jensen, E., \& Buckley, N. 2014. Why people attend science festivals: Interests, motivations and self-reported benefits of public engagement with research. Public Understanding of Science, 23(5), 557573. https://doi.org/10.1177/0963662512458624.

Joly, Y., Dalpé, G., So, D., \& Birko, S. 2015. Fair shares and sharing fairly: A survey of public views on open science, informed consent and participatory research in biobanking. PLoS ONE, 10(7), 1-21. https://doi.org/10.1371/journal.pone.0129893.

Kaslow, N. 2015. Translating Psychological Science to the Public. American Psychologist, 70(5), 361-371. https://doi.org/10.1037/ a0039448.

Kawamoto, S., Nakayama, M., \& Saijo, M. 2013. Using a scientific literacy cluster to determine participant attitudes in scientific events in Japan, and potential applications to improving science communication. Journal of Science Communication, 12(1), A01.

Kind, P. M., Jones, K., \& Barmby, P. 2010. Developing attitudes towards science measures. International Journal of Science Education, 29(07), 871-893. https://doi.org/10.1080/09500690600909091.

Knight, D. 2006. Public understanding of science: a history of communicating scientific ideas. Abingdon:Routledge.

Koolstra, C. M. 2008. An example of a science communication evaluation study: Discovery07, a Dutch science party. Journal of Science Communication, 7(2), 1-9.

Kuhn, D., Arvidsson, T. S., Lesperance, R., \& Corprew, R. 2017. Can Engaging in Science Practices Promote Deep Understanding of Them? Science Education, 101(2), 232-250. https://doi.org/10. $1002 /$ sce. 21263 .

Land-Zandstra, A. M., Devilee, J. L. A., Snik, F., Buurmeijer, F., \& van den Broek, J. M. 2016. Citizen science on a smartphone: Participants' motivations and learning. Public Understanding of Science, 25(1), 45-60. https://doi.org/10.1177/0963662515602406.

Lehmkuhl, M., Boyadjieva, P., Cunningham, Y., Karamanidou, C., Mörä, T., Schiebel, L., ... Trench, B. 2016. Audience reach of science on television in 10 European countries: An analysis of people-meter data. Public Understanding of Science, 25(2), 223-235. https://doi. org/10.1177/0963662514536295

Logan, R. A. 2001. Science Mass Communication: Its Conceptual History. Science Communication, 23(2), 135-163.

Logan, M., \& Skamp, K. 2008. Engaging Students in Science Across the Primary Secondary Interface: Listening to the Students' Voice. Research in Science Education, 38(4), 501-527. https://doi.org/10. 1007/s11165-007-9063-8.

Lörcher, I., \& Taddicken, M. 2017. Discussing climate change online. Topics and perceptions in online climate change communication in different online public arenas. Journal of Science Communication, 16(2), A03.

Luján, J. L., \& Todt, O. 2007. Precaution in public: the social perception of the role of science and values in policy making. Public 
Understanding of Science, 16(1), 97-109. https://doi.org/10.1177/ 0963662506062467.

Maier, M., Rothmund, T., Retzbach, A., Otto, L., \& Besley, J. C. 2014. Informal Learning Through Science Media Usage. Educational Psychologist, 49(2), 86-103. https://doi.org/10.1080/00461520. 2014.916215.

Majumder, M. A., Cook-Deegan, R., \& McGuire, A. L. 2016. Beyond Our Borders? Public Resistance to Global Genomic Data Sharing. PLoS Biology, 14(11), e2000206. https://doi.org/10.1371/journal. pbio.2000206.

Martiny, K. M., Pedersen, D. B., \& Birkegaard, A. 2016. Open Media Science. Journal of Science Communication, 15(06), A02.

Master, Z., Claudio, J. O., Rachul, C., Wang, J. C. Y., Minden, M. D., \& Caulfield, T. 2013. Cancer patient perceptions on the ethical and legal issues related to biobanking. BMC Medical Genomics, 6(8). https://doi.org/10.1186/1755-8794-6-8.

Masters, K., Oh, E. Y., Cox, J., Simmons, B., Lintott, C., Graham, G., ... Holmes, K. 2016. Science learning via participation in online citizen science. Journal of Science Communication, 15(03), A07.

McDermott, M., \& Kuhn, M. 2012. Communicating like a scientist with multimodal writing. Teaching Science: The Journal of the Australian Science Teachers Association, 58(2), 53-55.

Medvecky, F., \& Macknight, V. 2017. Building the economic-public relationship: learning from science communication and science studies. Journal of Science Communication, 16(2), A01.

Miller, J. D. 1998. The measurement of civic scientific literacy. Public Understanding of Science, 7(3), 203-223. https://doi.org/10.1088/ 0963-6625/7/3/001

Mizumachi, E., Matsuda, K., Kano, K., Kawakami, M., \& Kato, K. 2011. Scientists' attitudes toward a dialogue with the public: a study using "science cafes". Journal of Science Communication, 10(4), A02.

Morcillo, J. M., Czurda, K., \& Trotha, C. Y. R. 2016. Typologies of the popular science web video, 15(04).

Muñoz, A., Moreno, C., \& Luján, J. L. 2012. Who is willing to pay for science? On the relationship between public perception of science and the attitude to public funding of science, 21(2), 242-253. https:// doi.org/10.1177/0963662510373813

Navid, E. L., \& Einsiedel, E. F. 2012. Article Synthetic biology in the Science Café: what have we learned about public engagement? Journal of Science Communication, 11(4), A02.

Neresini, F., \& Bucchi, M. 2011. Which indicators for the new public engagement activities? An exploratory study of European research institutions. Public Understanding of Science, 20(1), 64-79. https:// doi.org/10.1177/0963662510388363.

Orthia, L. A. 2016. Democratizing science in the eighteenth century: resonances between Condorcet' s Sketch (1795) and twenty-first century science communication. Journal of Science Communication, 15(4), A04.

Osborne, J., Simon, S., \& Collins, S. 2003. Attitudes towards science: a review of the literature and its implications. International Journal of Science Education, 25(9), 1049-1079. https://doi.org/10.1080/ 0950069032000032199.

Owen, R., Macnaghten, P., \& Stilgoe, J. 2012. Responsible research and innovation: From science in society to science for society, with society. Science and Public Policy, 39(6), 751-760. https://doi.org/ 10.1093/scipol/scs093.

Parsons, T. 1951. The Social System. London:Routledge \& Kegan Paul Ltd.

Pinto, B., Marçal, D., \& Vaz, S. G. 2015. Communicating through humour: A project of stand-up comedy about science. Public Understanding of Science, 24(7), 776-793. https://doi.org/10. $1177 / 0963662513511175$

Post, S. 2016. Communicating science in public controversies: Strategic considerations of the German climate scientists. Public Understanding of Science, 25(1), 61-70. https://doi.org/10.1177/ 0963662514521542.
Prpic, K. 2011. Science, the public, and social elites: How the general public, scientists, top politicians and managers perceive science, 20(6), 733-750. https://doi.org/10.1177/0963662510366363

Ranger, M., \& Bultitude, K. 2016. 'The kind of mildly curious sort of science interested person like me': Science bloggers' practices relating to audience recruitment. Public Understanding of Science, 25(3), 361-378. https://doi.org/10.1177/0963662514555054.

Retzbach, A., \& Maier, M. 2015. Communicating Scientific Uncertainty: Media Effects on Public Engagement With Science. Communication Research, 42(3), 429-456. https://doi.org/10.1177/0093650214534967.

Retzbach, J., \& Otto, L. 2016. Measuring the perceived uncertainty of scientific evidence and its relationship to engagement with science, (2005). https://doi.org/10.1177/0963662515575253

Riesch, H., Potter, C., \& Davies, L. 2013. Combining citizen science and public engagement: The open airlaboratories programme. Journal of Science Communication, 12(3). https://doi.org/10.1016/j.ecoinf. 2011.03.002

Roger, E., \& Klistorner, S. 2016. BioBlitzes help science communicators engage local communities in environmental research. Journal of Science Communication, 15(3), A06.

Rowe, G., Rawsthorne, D., Scarpello, T., \& Dainty, J. R. 2010. Public engagement in research funding: a study of public capabilities and engagement methodology. Public Understanding of Science, 19(2), 225-239. https://doi.org/10.1177/0963662508096780.

RRI Tools. 2017. RRI Tools: project briefing sheet. Retrieved from https:/www.rri-tools.eu/documents/10184/16806/RRI+Tools+ Project+Brief.pdf/183c8a96-c414-4fab-80b9-31 ccecedaa47. Accessed 19 May 2017

Schäfer, M. S. 2009. From public understanding to public engagement: An empirical assessment of changes in science coverage. Science Communication, 30(4), 475-505. https://doi.org/10.1177/ 1075547008326943

Schäfer, M. S. 2011. Sources, characteristics and effects of mass media communication on science: a review of the literature, current trends and areas for future research. Sociology Compass, 5(6), 399-412. https://doi.org/10.1111/j.1751-9020.2011.00373.x.

Scharrer, L., Rupieper, Y., Stadtler, M., \& Bromme, R. 2016. When science becomes too easy: Science popularization inclines laypeople to underrate their dependence on experts. Public Understanding of Science, 25, 1-16. https://doi.org/10.1177/0963662516680311.

Scheufele, D. A., Corley, E. A., Shih, T., Dalrymple, K. E., \& Ho, S. S. 2009. Religious beliefs and public attitudes toward nanotechnology in Europe and the United States. Nature Nanotechnology, 4(2), 9194. https://doi.org/10.1038/nnano.2008.361.

Science and Technology Advisory Council. 2013. Science for an informed, sustainable and inclusive knowledge society. Brussels. Retrieved from http://ec.europa.eu/archives/commission 20102014/president/advisory-council/documents/stac_policy_paper no_1_290813.pdf. Accessed 3 Aug 2017

Shea, N. A. 2015. Examining the Nexus of Science Communication and Science Education: A Content Analysis of Genetics News Articles. Journal of Research in Science Teaching, 52(3), 397-409. https:// doi.org/10.1002/tea.21193.

Stiver, A., Barroca, L., Minocha, S., Richards, M., \& Roberts, D. 2015. Civic crowdfunding research: Challenges, opportunities, and future agenda. New Media \& Society, 17(2), 249-271. https://doi.org/10. $1177 / 1461444814558914$.

Stodden, V. 2010. Open science: policy implications for the evolving phenomenon of user-led scientific innovation. Journal of Science Communication, 9(1), A05.

Szu, E., Osborne, J., \& Patterson, A. D. 2016. Factual accuracy and the cultural context of science in popular media: Perspectives of media makers, middle school students, entertainment television program. Public Understanding of Science, 25, 1-16. https://doi.org/10.1177/ 0963662516655685. 
Takahashi, B., \& Tandoc Jr., E. C. 2016. Media sources, credibility, and perceptions of science: Learning about how people learn about science. Public Understanding of Scienceanding of Science, 25(6), 674-690. https://doi.org/10.1177/0963662515574986.

Tatalovic, M. 2009. Science comics as tools for science education and communication: a brief, exploratory study. Journal of Science Communication, 8(4), A02.

Thaler, A. D., \& Shiffman, D. 2015. Fish tales: Combating fake science in popular media. Ocean and Coastal Management, 115, 88-91. https://doi.org/10.1016/j.ocecoaman.2015.04.005.

Topham, J. R. 2009. Focus: historicizing "popular science" Introduction. Isis, 100(2), 310-318. https://doi.org/10.1086/599551.

Treise, D., \& Weigold, M. F. 2002. Advancing Science Communication: A Survey of Science Communicators. Science Communication, 23(3), 310-322. https://doi.org/10.1177/ 107554700202300306.

Turney, J. 2008. Popular science books. In M. Bucchi, \& B. Trench (Eds.), Handbook of Public Communication of Science and Technology (pp. 5-14). Abingdon: Routledge.

von Roten, F. C., \& Moeschler, O. 2007. Article Is art a "good" mediator in a Science Festival? Journal of Science Communication, 6(3), A2.

Watson, M. 2015. When will 'open science' become simply 'science'? Genome Biology, 16(101), 1-3. https://doi.org/10.1186/s13059015-0669-2.

Welbourne, D. J., \& Grant, W. J. 2016. Science communication on YouTube: Factors that affect channel and video popularity. Public Understanding of Science, 25(6), 706-718. https://doi.org/10.1177/ 0963662515572068 .
Publisher's Note Springer Nature remains neutral with regard to jurisdictional claims in published maps and institutional affiliations.

Martin Lakomý is a sociologist at the Institute of Population Studies of Masaryk University. His research interests include population ageing, changes in fertility behavior, and the connection of these processes to value changes. Martin studies these topics with quantitative data and does applied methodological research as well.

Renata Hlavová is a junior researcher at the Faculty of Social Studies, Masaryk University. She focuses mainly on quantitative data analyses, behavioural insights for education, and music psychology, specifically topics of everyday use of music and technologies, emotions, and wellbeing. She has participated in several national and international projects (such as Junior Researcher Programme or EU Kids Online).

Hana Machackova is a postdoc researcher at the Faculty of Social Studies, Masaryk University. She is a member of the Interdisciplinary Research Team on Internet and Society (IRTIS) and focuses on the area of cyberpsychology, specifically topics of online aggression, online communities, online participation, and health and well-being in relation to technology usage. This project has received funding from the European Union's Horizon 2020 research and innovation programme under Grant Agreement No. 741527. 